\title{
EFEITO DA LUZ ULTRAVIOLETA SOBRE A PRODUÇÃO DE ANTOCIANINAS EM CALOS DE BYRSONIMA GARDNERIANA A. JUSS
}

\author{
Thais Akemi Ogasawara da Silva ${ }^{1}$; Lenaldo Muniz de Oliveira ${ }^{2}$ e Katiane Oliveira \\ Porto $^{3}$ \\ 1. Bolsista PIBIC/CNPq, Graduando em Agronomia, Universidade Estadual de Feira de Santana, e-mail: \\ akemithais@hotmail.com \\ 2. Orientador, Departamento Biologia, Universidade Estadual de Feira de Santana, e-mail: lenaldo.uefs@ gmail.com \\ 3. Mestranda do PPGRGV, Universidade Estadual de Feira de Santana, e-mail: ksoliveira07@gmail.com
}

PALAVRAS-CHAVE: Malpighiaceae; Murici; cultivo in vitro.

\section{INTRODUÇÃO}

O gênero Byrsonima é o maior da família Malpighiaceae, agrupando espécies de grande importância medicinal, ornamental e produtoras de frutos comestíveis (RIBEIRO et al., 1999), sendo conhecidas popularmente como "murici". Entre as espécies deste gênero esta a Byrsonima gardneriana que é nativa e endêmica do Brasil, sendo distribuída nos domínios fitogeográficos da Amazônia, Caatinga, Cerrado e Mata atlântica (MAMEDE, 2017).

As espécies de Byrsonima apresentam grande potencial para a produção de antocianinas, capaz de atender à demanda comercial por corantes naturais, visto que seus frutos oferecem elevadas concentrações desse pigmento. As antocianinas são componentes do metabolismo secundário de plantas pertencentes ao grupo dos flavonoides e estão amplamente distribuídos na natureza (Volp et al., 2008). As funções desempenhadas pelas antocianinas nas plantas são variadas: atividade antioxidante, proteção à ação da radiação UV, mecanismo de defesa contra herbívoros, e processos reprodutivos, como a polinização e a dispersão de sementes (LOPES et al., 2007)

Buscando aliar o potencial dessa espécie ao interesse na produção do metabólito antocianina, o cultivo in vitro de células e tecidos vegetais constitui uma alternativa viável, em virtude das vantagens desse sistema de cultivo (FRANÇA, 2001). Nesse contexto, o cultivo de calos tem sido uma alternativa adequada para a produção de compostos de interesse, como as antocianinas (Rajendran et al., 1992).

Existe uma correlação positiva bem estabelecida entre intensidade de radiação solar e produção de compostos fenólicos, tais como as antocianinas ativas (GOBBO-NETO\& LOPES, 2007). Diante disso, o presente trabalho objetiva avaliar o efeito da exposição à luz ultravioleta sobre a produção in vitro de antocianina a partir de calos de Byrsonima gardneriana A. Juss.

\section{MATERIAL E MÉTODOS}

Os frutos de $B$. gardneriana tiveram seus endocarpos abertos para a retirada das sementes, as quais foram desinfestadas em câmara de fluxo laminar, através da imersão em álcool $70 \%$ por 30 segundos, seguido de hipoclorito de sódio a $1 \%$ acrescido de uma gota de detergente neutro por 10 minutos. Posteriormente, as mesmas foram inoculadas em tubos de ensaio contendo $10 \mathrm{~mL}$ de meio de cultura MS (MURASHIGE; SKOOG, 1962) com metade das concentrações salinas (MS/2), suplementado com 3\% de sacarose e solidificado com $0,7 \%$ de ágar. $\mathrm{O}$ pH do meio foi ajustado para $5,7 \pm 0,1$ antes da autoclavagem. Após as inoculações os tubos foram fechados com filme PVC e as culturas foram mantidas em sala de crescimento com temperatura de $25 \pm 3^{\circ} \mathrm{C}$, 
fotoperíodo de 16 horas, umidade relativa de $60 \%$ e radiação fotossintética ativa de 40 $\mu \mathrm{mol} \mathrm{m} \mathrm{m}^{-2}$.

Segmentos de folhas com aproximadamente $0,5 \mathrm{~cm}^{2}$ foram obtidos após 60 dias de cultivo, para servirem como explantes. Estes foram inoculados em meio de cultura MS suplementado com 3\% de sacarose e solidificado com 0,7\% de Agar e, para a indução dos calos, o meio foi suplementado com $16 \mu \mathrm{M}$ de BAP (6-benzilaminopurina) $+2 \mu \mathrm{M}$ de ANA (Ácido Naftaleno Acético). $\mathrm{O}$ pH do meio de cultura foi ajustado para $5,7 \pm 0,1$ antes da autoclavagem à temperatura de $121^{\circ} \mathrm{C}$ por 15 minutos. Os explantes foram inoculados em tubos de ensaio contendo $15 \mathrm{~mL}$ de meio de cultura, sendo mantidas em sala de crescimento, na ausência de luz por 30 dias pra indução dos calos.

Findado os 30 dias, as amostras de calos foram submetidas à exposição à luz ultravioleta $15 \mathrm{~W}$, em câmara de fluxo laminar, por diferentes intervalos de tempo $(0,2$, $4,8,16,32$ e 64 minutos). Após cada intervalo de tempo de exposição os calos foram cultivados em sala de crescimento com temperatura de $25 \pm 3^{\circ} \mathrm{C}$, fotoperíodo de 16 horas e radiação fotossintética ativa de $40 \mu \mathrm{mol} \mathrm{m} \mathrm{m}^{-2} \mathrm{~s}^{-1}$. Após 10 dias de cultivo foram coletadas amostras para quantificação do teor de antocianinas, utilizando-se três repetições com quatro amostras (4 tubos) em cada repetição.

O teor de antocianina foi avaliado em espectrofotômetro UV/VIS, efetuando-se leituras em comprimento de onda de $535 \mathrm{~nm}$. O conteúdo total de antocianinas foi expresso em mg de antocianinas/100g da fração da amostra analisada.

\section{RESULTADOS E DISCUSSÃO}

Durante o estabelecimento in vitro da espécie verificou-se baixa taxa de contaminação (1\%), demonstrando eficiência do protocolo de desinfestação, porém, a taxa de germinação foi de apenas $23 \%$, decorridos 60 dias da inoculação das sementes. Este fato, provavelmente, ocorreu em virtude da baixa viabilidade do lote de sementes utilizado ou devido à dormência nas sementes, comum em espécies do gênero, como mencionado por Lorenzi (2002) apud Nogueira et al. (2004).

Os segmentos foliares apresentaram, após 30 dias da inoculação na ausência de luz, todo explante recoberto por calo, sendo estes de coloração verde com regiões rosadas e textura compacta. A formação de calos com a utilização dos reguladores BAP e ANA também foi reportada por Pereira et al. (2012), que relataram a eficiência da utilização desses reguladores sobre a formação de calos em explantes foliares de Hyptis leucocephala.

Porém, apesar do sucesso na formação de calos com a utilização de BAP e ANA, a obtenção de calos com textura compacta, por serem altamente lignificados e firmes, não permite o estabelecimento de suspensões celulares, tipo de cultura mais adequada para produção de metabolitos secundários (PAIVA \& PAIVA, 2001). O efeito de diferentes concentrações de auxinas e citocininas vem sendo estudado para obtenção de calos friáveis para este fim, como por exemplo Nogueira et al (2007) que alcançou máxima porcentagem de calos friáveis a partir de segmentos foliares de Byrsonima intermedia utilizando 1,0 mg L-1 de 2,4-D.

O efeito da luz ultravioleta sobre a produção de antocianinas não foi distinta entre os tratamentos, não sendo detectados efeitos positivos da luz ultravioleta sobre a produção de antocianinas. Após a analise dos resultados, pôde-se observar que apenas a 
média do tratamento com tempo de exposição à luz igual à 2 minutos diferiu dos demais tratamentos, havendo redução no teor de antocianinas, significando, provavelmente, um possível erro de quantificação, haja visto que esse efeito não se manteve nos demais tempos de exposição.

Da mesma maneira, a análise dos dados demonstrou que a exposição dos calos à luz ultravioleta, pelos diferentes períodos de tempo, não afetou o acúmulo de biomassa, quantificado 10 dias após à exposição.

Apesar de não ter sido verificado o efeito da radiação ultravioleta sobre o crescimento dos calos e produção de antocianinas da espécie, outros trabalhos obtiveram resultados diferentes aplicando a luz ultravioleta. Ghanati et al (2013) observou que a aplicação da radiação UVC por 60 e 90 minutos aumentou significativamente o conteúdo de antocianinas em calos de Malve neglecta. Cetin (2014) obteve maior teor total de flavonoides a partir da exposição dos calos de Vitis vinífera a radiação UVC durante 5 minutos.

A radiação UVC atua como um fator de estresse e assim ativa alguns mecanismos de defesa dos tecidos vegetais, como o acumulo de compostos fenólicos (BARKA, 2001). Porém, para ativar estes mecanismos é preciso se considerar a intensidade da radiação, o tempo de exposição à luz e também o numero de aplicações. Crizel (2012) ao usar 24 e 34 aplicações da radiação UVC com intensidade de 3,7 kJ.m

2 durante o cultivo de morangos das cultivares Aromas e Albion conseguiu promover aumento nos teores de antocianinas.

Assim, uma possível explicação para o fato de não se ter detectado efeito da radiação, nos períodos testados, sobre os calos da espécie Byrsonima gardneriana é que a intensidade da radiação UVC emitida pela lâmpada bem como o tempo de exposição pode não ter sido suficiente para induzir a expressão gênica das enzimas da rota biossintética dos fenilpropanóides, responsáveis pelo aumento da produção de metabolitos de função protetora contra a foto destruição, como mencionado por Gobbo Neto e Lopes (2007). Outra possível razão pode ter sido a pequena sensibilidade do método adotado, exclusivo para antocianinas, contudo, existem uma gama de compostos fenólicos que não foram quantificados e podem ter sido estimulados.

\section{CONSIDERAÇÕES FINAIS}

É possível a indução de calos da espécie Byrsonima gardneriana utilizando segmentos de folhas e os reguladores de crescimento BAP e ANA. Nas condições experimentais adotadas não se verificou efeito da radiação ultravioleta sobre $o$ crescimento dos calos e produção de antocianinas da espécie. Novos experimentos devem ser conduzidos avaliando-se diferentes intensidades de radiação, bem como maiores tempos de exposição.

\section{REFERÊNCIAS}

LOPES, T. J; XAVIER, M. F.; QUADRI, M. G. N.; QUADRI, M. B. Antocianinas: uma breve revisão das características estruturais e da estabilidade. R. Bras. Agrociência, Pelotas, v.13, n.3, p. 291-297, 2007.

MAMEDE, M.C.H. Byrsonima in: Lista de Espécies da Flora do Brasil. Jardim Botânico do Rio de Janeiro. Disponível em: 
<http://floradobrasil.jbrj.gov.br/jabot/floradobrasil/FB8827>. Acesso em: 16 Março. 2017.

RIBEIRO, J.E.L.S., HOPKINS, M.J.G., VICENTINI, A., SOTHERS, C.A., COSTA, M.A.S., BRITO, J.M., SOUZA, M.A.D., MARTINS, L.H.P., LOHMANN, L.G., ASSUNÇÃO, P.A.C.L., PEREIRA, E.C., SILVA, C.F., MESQUITA, M.R. \& PROCÓPIO, L.C. Floresta da reserva Ducke: guia de identificação das plantas vasculares de uma floresta de terra-firme na Amazônia Central. Inpa, Manaus, p.505$511,1999$.

Volp ACP, Renhe IRT, Barra K \& Stringueta PC. Flavonóides antocianinas: características e propriedades na nutrição e saúde. Revista Brasileira de Nutrição Clinica, 23:141-149, 2008.

FRANÇA, S.C. Abordagens biotecnológicas para a obtenção de substâncias ativas. In: SIMÕES et al Farmacognosia da planta ao medicamento. 3. ed. Porto Alegre: Editora da UFSC, capítulo 7, p. 105-124, 2001.

RAJENDRAN, L.; RAVISHANKAR, G. A.; VENKATARAMAN, L. V.; PRATHIBA, K. R. Anthocyanin production in callus cultures of daucus carota as influenced by nutrient stress and osmoticum. Biotechnology Letters v. 14 No.8. pp.707-712, 1992.

GOBBO-NETO, L.; LOPES, N. P. Plantas medicinais: fatores de influência no conteúdo de metabólitos secundários. Química nova, v. 30, n. 2, p. 374, 2007.

MURASHIGE, T.; SKOOG, F. A revised medium for a rapid growth and bioassays with tabacco tissue cultures. Physiologia Plantarum. 15:493-497, 1962.

NOGUEIRA, R. C.; PAIVA, R.; CASTRO, A. H.; VIEIRA, V. C.; ABBADE, L. C.; ALVARENGA, A. A. Germinação in vitro de murici-pequeno (Byrsonima intermedia A. Juss.). Ciênc. agrotec., Lavras, v. 28, n. 5, p. 1053-1059, 2004.

PEREIRA, D. M. S.; OLIVEIRA, L. M.; NEPOMUCENO, C. F.; SANTANA, J. R. F.; SILVA, M. L. C.; KOBLITZ, M. G. B. Indução e caracterização morfológica e bioquímica de calos de Hyptis leucocephala (Lamiaceae). Sitientibus série Ciências Biológicas 12(1): 151-156, 2012.

GHANATI, F., F. KHATAMI AND E. BEMANI. Effects of UV B and UV C radiation on viability, growth, and major natural compounds of Malve neglecta L. cells. Iranian Journal of Plant Physiology 4 (1), 881-887, 2013.

CETIN, E. S. Induction of secondary metabolite production by UV-C radiation in Vitis vinífera L. Okuzgozu callus cultures. Bioological Research, 2014.

BARKA, E. A. Protective enzymes against reactive oxygen species during ripening of tomato (Lycopersicon esculentum) fruits in response to low amounts of UV-C. Australian Journal of Plant Physiology, v. 28, p. 785-791, 2001.

CRIZEL, G. R. Efeito da radiação UV-C durante o cultivo de morangos: aspectos bioquímicos-fisiologicos e tecnológicos. Dissertação (Mestrado) - Universidade Federal de Pelotas, Pelotas, 2012.

PAIVA, R.; PAIVA, P. D. O. Cultura de Tecidos. 97p. UFLA/FAEPE, 2001.

NOGUEIRA, R. C.; PAIVA, R.; OLIVEIRA, L. M.; SOARES, G. A.; SOARES, F. P.; CASTRO, A. H. F.; PAIVA, P.D.O. Indução de calos em explantes foliares de muricipequeno (Byrsonima intermedia A. Juss.) Ciênc. agrotec., Lavras, v. 31, n. 2, p. 366370, 2007. 